\title{
Post-mortem findings in critically ill patients treated with continuous renal replacement therapy
}

\author{
IA Crippa*, J Gleeson, V Fontana, J-L Vincent, J Creteur, FS Taccone \\ From ESICM LIVES 2015 \\ Berlin, Germany. 3-7 October 2015
}

\begin{abstract}
Introduction
Despite the high incidence of acute kidney injury (AKI) in critically ill patients, studies evaluating histopathological renal findings in these patients yielded inconsistent results. No studied specifically evaluated renal histology in intensive care unit (ICU) patients treated by continuos renal replacement therapy for severe AKI.
\end{abstract}

\section{Objectives}

To describe histopathological findings in patients treated with CRRT for severe AKI.

\section{Methods}

We retrospectively identified all patients admitted to our department of Intensive Care during a two-year period (2012-2013) who required CRRT at any time during ICU stay, who died and had post-mortem (PM) examination. Predefined exclusion criteria were: history of end-stage kidney disease requiring dialysis before admission, CRRT required for any reason other than kidney failure and death in the first 24 hours of admission. Kidney histology examination was by light microscopy only.

\section{Results}

Thirty-two post-mortem examinations were performed within 24 hours of death. Mean age was 63 [53-67] years; $12 / 32$ patients (37\%) had arterial hypertension and 9/32 patients $(28 \%)$ had past medical history of chronic kidney disease. The most common ICU diagnosis was severe sepsis/septic shock (14/32; 44\%), cardiogenic shock (6/32; $19 \%)$ or liver failure (3/32; $9 \%)$. Post-mortem autolysis precluded analysis in 4 patients and these were excluded from further analysis. Acute tubular necrosis (ATN) was the clinical diagnosis in 21/28 (75\%) patients. However, histological features of ATN were only seen in 5 of these.

Erasme University Hospital, Bruxelles, Belgium
There was significant discordance between the clinical and histological renal diagnosis in 6 patients; 3 had unexpected chronic pyelonephritis, 1 had bilateral renal infarction, 1 had septic emboli and 1 had acute interstitial nephritis. Background atherosclerotic reno-vascular disease was common (32\%). Nine patients had normal kidneys at PM examination (32\%).

\section{Conclusions}

ATN is a rare pathological finding in renal PM analysis of ICU patients treated with CRRT for severe AKI. One fifth of patients had an unanticipated renal pathology. Normal renal parenchyma was found in one third of all patients.

Published: 1 October 2015

doi:10.1186/2197-425X-3-S1-A841

Cite this article as: Crippa et al:: Post-mortem findings in critically ill patients treated with continuous renal replacement therapy. Intensive Care Medicine Experimental 2015 3(Suppl 1):A841.

\section{SpringerOpen $^{\odot}$}

(c) 2015 Crippa et al.; This is an Open Access article distributed under the terms of the Creative Commons Attribution License (http:// creativecommons.org/licenses/by/4.0), which permits unrestricted use, distribution, and reproduction in any medium, provided the original work is properly cited.
Submit your manuscript to a SpringerOpen ${ }^{\circ}$ journal and benefit from:

- Convenient online submission

- Rigorous peer review

- Immediate publication on acceptance

- Open access: articles freely available online

- High visibility within the field

- Retaining the copyright to your article

Submit your next manuscript at $>$ springeropen.com 